\title{
MEASURING THE DYNAMIC EFFICIENCY COSTS OF REGULATORS' PREFERENCES: MUNICIPAL WATER UTILITIES IN THE ARID WEST
}

\author{
By CHRISTOPHER TIMMINs ${ }^{1}$
}

\begin{abstract}
Evidence suggests that municipal water utility administrators in the western US price water significantly below its marginal cost and, in so doing, inefficiently exploit aquifer stocks and induce social surplus losses. This paper empirically identifies the objective function of those managers, measures the deadweight losses resulting from their price-discounting decisions, and recovers the efficient water pricing policy function from counterfactual experiments. In doing so, the estimation uses a "continuous-butconstrained-control" version of a nested fixed-point algorithm in order to measure the important intertemporal consequences of groundwater pricing decisions.
\end{abstract}

KEYWORDS: Groundwater, dynamic program, nested fixed-point algorithm, publicly provided private goods, in situ shadow value.

\section{INTRODUCTION}

WATER RESOURCES in the western United States have traditionally been priced below their marginal cost of production in both agricultural and urban applications, even in regions where virtually all water is imported or pumped from slowly recharging underground pools. Consider, for example, the water provided to urban users by a specific type of water utility-the municipally owned and operated firms that comprise approximately $85 \%$ of all water companies nationwide (Mann and Mikesell (1976)). In the most water-scarce regions of the West, these utilities are forced to rely primarily, if not entirely, on groundwater for their raw water supplies. The administrators of these utilities are more than just water purveyors; they are managers of valuable renewable resource stocks, and the groundwater extraction decisions they make today influence the cost of and constraints on the extraction decisions that they will make tomorrow. Their decisions are made in a dynamic context.

Evidence suggests that these water utility administrators price municipal water significantly below its marginal cost and, in so doing, inefficiently exploit aquifer stocks and induce social surplus losses. On allocational efficiency grounds, water is extracted from the aquifer "too quickly." This paper empirically identifies the objective function of municipal managers that underlines these price-discounting decisions, measures the deadweight losses resulting from those decisions, and

${ }^{1}$ I gratefully acknowledge the comments received from Doug Brown, Larry Goulder, Ken Judd, Tom MaCurdy, Ariel Pakes, John Rust, Buzz Thompson, Frank Wolak, a co-editor, an anonymous referee, and all the participants in the Applied Microeconomics, Industrial Organization, and Environment Workshops at Stanford and Yale Universities. Any remaining errors or omissions are my own. 


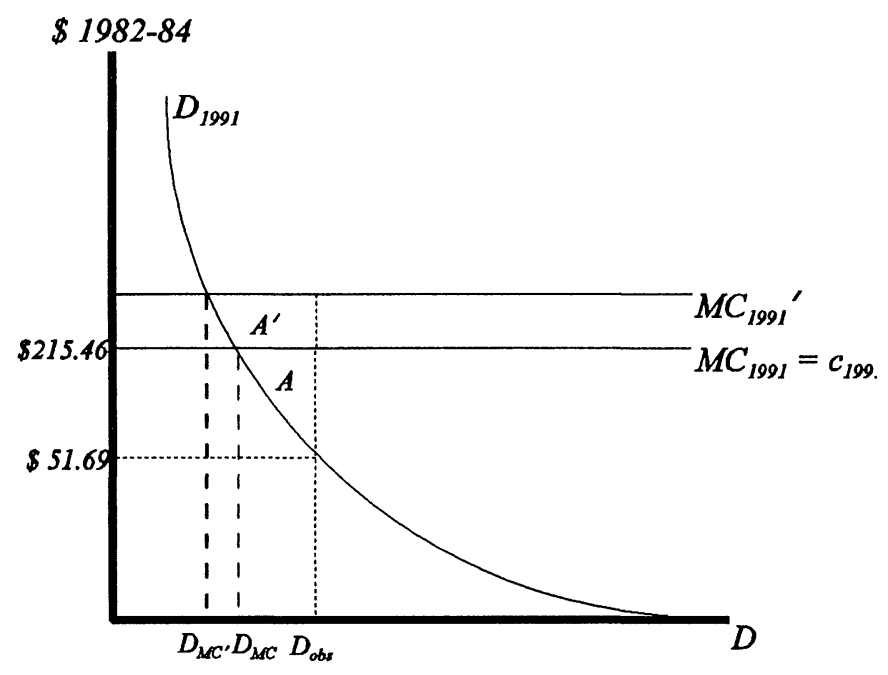

FIGURE 1.

recovers the efficient pricing policy function from counterfactual experiments. Unlike previous studies (Renzetti (1992), Swallow and Marin (1988), Feldman, Breese, and Obeiter (1981)) it does so in an empirical context that acknowledges the important intertemporal consequences of the pricing decisions made by the managers of groundwater dependent municipalities.

\subsection{Evidence on Inefficient Pricing}

Water in California's cities is regularly sold at prices well below its marginal cost of production, with adverse consequences for allocational efficiency. To illustrate this, consider a particular city: Delano, California. Located in the southern end of California's San Joaquin Valley, this city owned and operated the water utility that served its municipal population of approximately 20,000 residents in 1991. Observing the welfare loss imposed by its inefficient pricing behavior and considering how that loss would be compounded if its problem were to be viewed in an intertemporal context will motivate the dynamic estimation algorithm that follows.

For reasons discussed below, a semilog specification has desirable properties for modeling municipal water demand. Making use of the data panel discussed in Section 3, estimates of municipal demand are obtained in Section 4; with those estimates, a fitted inverse water demand curve can be constructed for the city of Delano in 1991: $P_{1991}=1187-133 \ln D_{1991}$ (in real 1982-84 dollars) ${ }^{2}$ (see Figure 1). Assuming for illustrative purposes that (i) in its operations, the city

${ }^{2} D$ is measured in acre-feet, the volume of water needed to cover one acre of ground at a depth of one foot. One acre-foot equals 43,560 cubic feet or 325,851 gallons. 
TABLE I

Marginal Costs and Prices, Averages By City

(CONSTANT 1982-84 DOllars)

\begin{tabular}{lccc}
\hline \hline City & Obs & $M C_{i, t}-P_{i, t}$ & $\left(M C_{i, t}-P_{i, t}\right) / M C_{i, t}$ \\
\hline Clovis & 16 & $19.67^{* * *}$ & 0.087 \\
Delano & 15 & $118.60^{*}$ & 0.818 \\
Dinuba & 15 & $97.69^{*}$ & 0.406 \\
Exeter & 22 & $47.74^{*}$ & 0.468 \\
Firebaugh & 14 & $174.40^{*}$ & 1.000 \\
Fresno & 19 & $124.99^{*}$ & 1.000 \\
Hanford & 21 & $65.15^{*}$ & 0.449 \\
Kerman & 6 & $109.44^{*}$ & 1.000 \\
Madera & 16 & $124.46^{*}$ & 1.000 \\
Mendota & 15 & $101.50^{*}$ & 0.446 \\
Reedley & 17 & $171.14^{*}$ & 1.000 \\
Sanger & 16 & $43.88^{*}$ & 0.410 \\
Shafter & 15 & $120.61^{*}$ & 1.000 \\
\hline
\end{tabular}

Notes: ${ }^{* * *}$ indicates statistical significance at the $10 \%$ level, ${ }^{* *}$ indicates significance at the $2.5 \%$ level, and * indicates significance at the $0.5 \%$ level. All figures are reported in constant 1982-84 dollars.

of Delano produced water with constant marginal costs, and (ii) all its variable costs were observed in the data without error, Delano's static marginal cost in 1991 could be calculated to be $\$ 215.46$ per acre-foot. At that time, however, the marginal price it charged for an acre-foot of water was only $\$ 51.69$, resulting in a fitted annual municipal demand of 4,955 acre-feet (denoted by $D_{o b s}$ ). This observed price-output pair is in marked contrast to that which would have been realized under a myopic marginal cost pricing policy $\left(P_{M C}=\$ 215.46\right.$ per acre-foot and $D_{M C}=1,452$ acre-feet). Compared with such a policy and considering only current period costs, the observed pricing behavior creates a static deadweight efficiency loss of area $A$, with a value of $\$ 331,777$. Other cities in other years exhibit similar behavior. ${ }^{3}$ Table I illustrates the mean discount of price below marginal cost (alone and relative to marginal cost) granted by each city over years when sufficient operating cost and output data were available.

Were each city under consideration to use only purchased raw water supplies, a static measurement like that shown in Table I might be sufficient to measure the inefficiency costs imposed by its manager's price-discounting decisions. Raw water would be an input to the water-provision process no different from labor or energy. However, Delano, like every other city in my panel, obtained its raw water supplies from renewable groundwater stocks. Extraction from these stocks today involves not only current costs but also increased pumping costs in the future; i.e., the removal of water from an aquifer, ceteris paribus, increases the height its remaining stock must be lifted to the surface at every point in time thereafter, and the greater that "lift-height," the more expensive pumping becomes. When

\footnotetext{
${ }^{3}$ In fact, approximately one-half of all cities observed in the data panel charge a marginal price of zero.
} 
myopic agents ignore this effect, they extract more than the dynamically optimal quantity of water. Were Delano forward-looking in its extraction decisions, the city's management would instead recognize that its marginal cost curve was actually $M C_{1991}^{\prime}$ :

$$
M C_{1991}^{\prime}=M C_{1991}+E_{1991}\left[\sum_{t=1992}^{\infty} \beta^{t-1991} \frac{\partial C_{t}^{\prime}}{\partial D_{1991}}\right]
$$

where $D_{1991}$ is groundwater extraction in 1991 and $\partial C_{t}^{\prime} / \partial D_{1991}$ measures the increase in year- $t$ costs arising from that extraction (i.e., through its intertemporal effect on lift-height, $\left.\partial C_{t}^{\prime} / \partial D_{1991}=\partial C_{t}^{\prime} / \partial h_{t} \cdot \partial h_{t} / \partial D_{1991}\right)$, assuming that the utility prices according to a dynamically efficient price schedule in every future period. The static marginal cost curve would no longer be sufficient to measure the welfare loss induced by the municipality's price-discounting behavior. Specifically, those inefficiency costs would be understated by area $A^{\prime}$ (see Figure 1). This is an economically significant result. As will be demonstrated below, if we were to ignore $A^{\prime}$ and focus only on $A$, we would overlook more than $70 \%$ of the total welfare costs of municipal managers' inefficient water pricing decisions.

\subsection{Methodology}

Methodologically, this paper first specifies an objective function that rationalizes municipal managers' inefficient pricing decisions as the outcome of optimizing behavior. This raises a question that has already been asked by numerous political-economic analyses; i.e., what form of payoffs do municipal managers maximize? From a cursory inspection of the data in Table I, it is apparent that they do not price water to maximize either profits or net social surplus. In the following exercise, a flexible payoff function, which nests several possible objectives while allowing municipal managers to account for the dynamic implications of their actions, is used instead. The degree to which that mixed objective is pursued relative to simpler objectives (e.g., consumer surplus or revenue maximization) is then recovered from observed behavior.

Specifically, a data panel describing the pricing decisions of a group of thirteen municipal water utilities in a groundwater dependent region of California is used to identify the trade-off between the needs of taxpayers and water consumers that is faced by municipal managers. In practical terms, this involves the estimation of a structural system of water supply and demand equations. Given the intertemporal nature of the manager's decisions, a set of conditional policy functions, defined over groundwater stocks, constitutes a city's supply schedule. A nested fixed-point algorithm is used to identify the structural parameters underlying this system. That algorithm is original in that it (i) preserves the natural continuity of the municipal manager's decision variable (i.e., the marginal price of urban water), as would an estimable Euler equation, while (ii) making efficient use of predominantly constrained municipal water price data (where Eulerequation techniques cannot) and (iii) allowing unobservable shocks to municipal 
water production to be correlated over time. Estimation is complicated by the fact that available data do not describe every element of municipalities' costs and revenues from water provision. The parameters of the flexible payoff function must therefore be estimated concurrently with a set of parameters that characterize the distribution of unobserved costs and revenues.

Once recovered, the structural parameters underlying the behavior of water utility managers and municipal consumers are used to conduct simulations that answer the following questions. (i) How would currently charged water prices need to be altered in order to implement a dynamically efficient pricing policy, how would those prices adjust over time, and how would they compare to efficient prices that ignored the dynamic cost components associated with aquifer management? (ii) What would be the Pareto improvement in net aggregate surplus from dynamic efficient pricing? (iii) What would be the savings in municipal revenues, which translate into gains to taxpayers, from a dynamic efficient pricing policy? (iv) What would be the costs to consumers of water (aside from their simultaneous role as taxpayers) in terms of lost surplus from that policy?

This paper is organized as follows. Section 2 describes the model that is used to quantify municipal managers' behavior, and Section 3 discusses the data panel that is used to estimate that model. Section 4 derives the likelihood function, describes the two-stage nested fixed-point algorithm that maximizes it, and reports parameter estimates. In Section 5, those estimates are used to conduct counterfactual simulations of efficient pricing policies. Section 6 summarizes the paper's conclusions.

\section{THE MODEL}

Econometric analysis of the municipal manager's payoff function in a dynamic context requires a simply parameterized model. The water utility's production process consists of three stages: raw water acquisition, treatment, and distribution. The cities under consideration acquire raw water inputs solely from pumped groundwater. The costs incurred in this pumping activity are modeled structurally, while those arising from the other two stages of production are modeled in a reduced form. The municipal utility also operates subject to a physical relationship that governs the size of its groundwater stock, i.e., the water contained in its underlying aquifer at the conclusion of each year equals the water contained therein at the outset, less any water extracted, plus any water recharged through natural or artificial means, plus or minus any water that enters or exits because of subterranean flow-gradients.

Like most water utilities in the United States, the producers in my sample must provide all the water that is demanded of them by urban customers according to potentially nonlinear rate schedules that they choose for the duration of a year. As far as the provision of water is concerned, each municipality is comprised of both a "regulated firm" (i.e., the engineering and public-works departments of the municipal water utility) and a "regulator" (i.e., the rate-setting municipal finance department acting in conjunction with elected officials). Observed 
rate-setting behavior is simply the equilibrium outcome of an unobserved regulatory process that goes on between these groups. The model assumes that each municipality's regulator chooses a rate schedule each year in order to maximize a discounted stream of payoffs from groundwater provision, while accounting for the effect of current extraction activities on future extraction costs through the impact of those activities on the available groundwater stock.

Subsections 2.1-2.4 detail each component of the hypothesized pricing decision of the municipal producer and the demand behavior of the municipal aggregate. Subsection 2.5 summarizes these components with the utility's dynamic objective function and relates that function to objectives typically employed in regulation studies. Subsection 2.6 discusses a number of additional assumptions that are required in order to identify the parameters of this dynamic objective function.

\subsection{Municipal Demand}

Usually included among the determinants of municipal water demand are population, income (which, aside from having a direct effect, also proxies for household appliance stock), climate variables such as temperature and rainfall, and numerous measures of price, which describe nonlinear tariff schedules (Agthe and Billings (1980), Carver and Boland (1980), Howe (1982), Billings (1982), Cochran and Cotton (1985), Martin and Wilder (1992)). Water demand is modeled in this paper at the level of the municipality for city $i$ in year $t\left(D_{i, t}\right)$, assuming that residential use, which comprises $64 \%$ of all urban demand (California DWR (1994a, p.154)), will vary proportionally with all other uses of water (i.e., commercial, governmental, and industrial) in a city. Specifically, municipal water demand is treated as a function of the number of residential connections served, the marginal price of water, "virtual" household income (i.e., real median household income plus the value of the additional payments that would have been made for all inframarginal water had it too been priced at the marginal rate), and a substitute for outdoor groundwater use (i.e., rainfall).

It is no easy matter to define the water price faced in a municipal market. Consumers are heterogeneous and, even within the residential class, can be charged according to different rate structures (e.g., flat, increasing-block, decreasingblock). In order to proceed with the analysis, I therefore characterize the "typical" rate structure employed in my panel cities with three components: (i) a service charge $\left(\psi_{i, t}\right)$, payment of which entitles a household in city $i$ in fiscal year $t$ to (ii) some quantity of water $\left(w_{i, t}\right)$, and (iii) a marginal rate $\left(P_{i, t}\right)$ charged for each acre-foot of water consumed beyond $w_{i, t}$. Together, $\left(\psi_{i, t}, w_{i, t}\right)$ determine the full inframarginal charge, which is used to calculate virtual income $\left(I N C_{i, t}\right)$. Municipal demand is given by

$$
\begin{aligned}
\ln D_{i, t}= & \delta_{0}+\text { citdum' }^{\prime} \delta_{0, i}-\delta_{1} P_{i, t}+\delta_{2} I N C_{i, t}-\delta_{3} R_{i, t} \\
& +\delta_{4} S_{i, t}+\varepsilon_{i, t}^{d}, \quad \varepsilon_{i, t}^{d} \sim \text { i.i.d. } N\left(0, \sigma_{d}^{2}\right),
\end{aligned}
$$

where citdum' is a vector of city-specific dummy variables, $S_{i, t}$ measures the number of active residential service connections, $R_{i, t}$ is annual rainfall (mea- 
TABLE II

Distribution of Marginal Price Per Acre-Foot, Full Data Panel

$(n=195$, CONSTANT 1982-84 DOLLARS $)$

\begin{tabular}{llrllllcc}
\hline \hline Percentile & 0 & 48.2 & 50 & 60 & 70 & 80 & 90 & 95 \\
Price & 0.0 & 0.0 & 19.61 & 50.51 & 73.35 & 99.96 & 119.19 & 149.69 \\
\hline
\end{tabular}

sured in inches), and $\varepsilon_{i, t}^{d}$ is a stochastic component of municipal demand that accounts for water uses such as extinguishing fires. This semilog specification provides a reasonable representation of municipal water demand: the marginal willingness to pay for an additional unit of water becomes infinite as the quantity consumed approaches zero and becomes zero at a finite level of consumption. This latter characteristic is appropriate given water's high storage cost and legal prohibitions against its resale. Unlike an isoelastic demand specification, it also allows data to be used from cities that charge a "flat rate" (i.e., a marginal price of $P=0$ along with a service charge that does not depend on consumption). Such pricing behavior is observed in approximately one-half of the data panel. (See Table II)

Rainfall introduces an additional element of uncertainty into urban water demand as it is perceived by the municipal government at the beginning of each fiscal year when it sets its rate schedule. The government is ascribed rational expectations of demand given its knowledge of the demand parameters and the process driving rainfall. Based on over sixty years of data, Box-Pierce statistics indicate that annual rainfall in each of three representative cities in the San Joaquin Valley cannot be individually differentiated from white noise. OLS was therefore performed on the following equation for each of these cities:

$$
R_{i, t}=\mu_{i}^{R}+\varepsilon_{i, t}^{R}, \quad \varepsilon_{i, t}^{R} \sim \text { i.i.d. } N\left(0, \sigma_{R, i}^{2}\right)
$$

The expected market demand for water, as perceived by the municipal government at the start of fiscal year $t$, given its knowledge of the parameters underlying demand, is thus: ${ }^{4}$

$$
\begin{aligned}
& E_{\varepsilon_{i, t}^{R}, \varepsilon_{i, t}^{d}}\left[D_{i, t} \mid P_{i, t}, I N C_{i, t}, \mu_{i}^{R}, S_{i, t} ; \bar{\delta}\right] \\
& \quad=E_{\varepsilon_{i, t}^{R} \varepsilon_{i, t}^{d}}\left[e^{\left.\delta_{0}+\text { citdum }^{\prime} \delta_{0, i}-\delta_{1} P_{i, t}+\delta_{2} I N C_{i, t}-\delta_{3} \mu_{i}^{R}+\delta_{4} S_{i, t}-\delta_{3} \varepsilon_{i, t}^{R}-\varepsilon_{i, t}^{d}\right],}\right. \\
& {\left[\begin{array}{c}
\varepsilon_{i, t}^{R} \\
\varepsilon_{i, t}^{d}
\end{array}\right] \sim \text { i.i.d. } N\left[\left(\begin{array}{c}
0 \\
0,
\end{array}\right)\left(\begin{array}{cc}
\sigma_{R, i}^{2} & 0 \\
0 & \sigma_{d}^{2}
\end{array}\right)\right] .}
\end{aligned}
$$

${ }^{4}$ At this and several other points in the econometric model, covariances in the error structure are restricted to be zero. These assumptions are not ideal but are made for identification purposes given the limited number of observations in the full panel (195) and the large number of parameters to be estimated (68). With additional data, these restrictions should certainly be relaxed. 


\subsection{Groundwater Stocks}

The variation from year to year in lift-height measures the change in a city's groundwater stock. $h_{i, t+1}$ (i.e., city $i$ 's lift-height at the start of fiscal year $t+1$ or at the end of fiscal year $t$ ), is assumed to be a linear function of (i) the quantity of water the city removes from the aquifer during fiscal year $t\left(D_{i, t}\right)$, (ii) natural recharge $\left(\gamma_{1}+\right.$ citdum $\left.^{\prime} \gamma_{1, i}\right)$ and any water the city adds to the aquifer through artificial means that year $\left(\right.$ rech $\left._{i, t}\right)$, (iii) the starting lift-height in fiscal year $t\left(h_{i, t}\right)$, (iv) rainfall in fiscal year $t-1\left(R_{i, t-1}\right)$, (v) the gradient driving subsurface water flow in the aquifer $\left(A V G_{i, t}\right),{ }^{5}$ and (vi) a source of stochastic variation in liftheight, $\varepsilon_{i, t}^{h} \sim$ i.i.d. $N\left(0, \sigma_{h}^{2}\right)$. rech ${ }_{i, t}$ is assumed to be known by the managers of city $i$ at the start of fiscal year $t$.

From the city's perspective at the outset of fiscal year $t$, its expected end-ofyear lift-height, given its choice of $P_{i, t}$ and its subsequent expectation of demand, is described by:

$$
\begin{aligned}
& E_{\varepsilon_{i, t}^{h}, \varepsilon_{i, t}^{R}, \varepsilon_{i, t}^{d}}\left[h_{i, t+1} \mid h_{i, t}, P_{i, t}, I N C_{i, t}, \mu_{i}^{R}, S_{i, t}, \operatorname{rech}_{i, t}, R_{i, t-1}, A V G_{i, t} ; \bar{\gamma}\right] \\
& =E_{\varepsilon_{i, t}^{h}, \varepsilon_{i, t}^{R}, \varepsilon_{i, t}^{d}}\left[\gamma_{0} h_{i, t}+\gamma_{1}+\text { citdum }^{\prime} \gamma_{1, i}+\gamma_{2} D_{i, t}-\gamma_{2,4} \text { rech }_{i, t}\right. \\
& \left.\quad-\gamma_{3} R_{i, t-1}-\gamma_{4} A V G_{i, t}+\varepsilon_{i, t}^{h}\right] .
\end{aligned}
$$

\subsection{Pumping Costs}

Since groundwater represents the sole source of raw water supply in each of the cities under consideration, the cost of water acquisition is described by the groundwater pumping-cost function. A Cobb-Douglas parameterization of those costs is employed. All cities are assumed to operate the cost-minimizing number and placement of pumps. $\varepsilon_{i, t}^{g} \sim$ i.i.d. $N\left(0, \sigma_{g}^{2}\right)$ represents a stochastic source of variation in the cost of groundwater pumping.

From the municipality's perspective at the outset of fiscal year $t$, unobservables introduce an additional stochastic component into pumping costs. Municipal managers therefore choose an optimal price in fiscal year $t$ given their expectation of the cost of extraction in that year:

$$
\begin{gathered}
E_{\varepsilon_{i, t}^{h}, \varepsilon_{i, t}^{R}, \varepsilon_{i, t}^{d}}\left[C^{g}\left(h_{i, t}, P_{i, t}, I N C_{i, t}, \mu_{i,}^{R}, S_{i, t}, \varepsilon_{i, t}^{R}, \varepsilon_{i, t}^{d}, \varepsilon_{i, t}^{g} ; \bar{\alpha}\right)\right] \\
=E_{\varepsilon_{i, t}^{h}, \varepsilon_{i, t}^{R}, \varepsilon_{i, t}^{d}}\left[e^{\left(\alpha_{0}+\operatorname{citdum}^{\prime} \alpha_{0, i}+\varepsilon_{i, t}^{g}\right)} \cdot h_{i, t}^{\alpha_{1}} \cdot D_{i, t}^{\alpha_{2}}\right] .
\end{gathered}
$$

${ }^{5} A V G_{i, t}$, the average of the differences between the aquifer heights in the agricultural quartertownships surrounding a given city $\left(A_{j, t}, j=1,2, \ldots, J\right)$ and the aquifer height of that particular city $\left(A_{i, t}\right)$ in year $t$, is given by

$$
A V G_{i, t}=\frac{1}{J} \sum_{j-1}^{J}\left(A_{j, t}-A_{i, t}\right)
$$

$A V G_{i, t}>0$ indicates a "cone of depression" under city $i$, which will lead to an inflow of water from surrounding quarter-townships in the following period. This treatment of the common pool properties of the aquifer ignores the possibility of gaming between cities and surrounding farmers for water, but is maintained owing to data and computational constraints. 


\subsection{Other Costs and Revenues}

The cities being studied incur operating costs other than those from groundwater pumping and derive revenues other than those obtained from typical residential water sales. For example, municipal utilities incur expenses in the treatment, pressurization, and distribution of water, and may earn additional revenues from special contracts with large industrial users. While these additional costs and revenues must appear explicitly in the utility's variable profit function, the data required to model them structurally are not available. Nonpumping costs of operation are therefore assumed to be a linear function of output:

$$
C_{i, t}^{N P}=\left(c_{i}+\chi_{i, t}\right) \cdot D_{i, t}
$$

where $c_{i}$ measures a time-invariant component of city $i$ 's marginal cost that can be recovered from data, and $\chi_{i, t}$ represents unobserved components of marginal cost that vary across time and location.

Variable revenues from water sales are assumed to be of the form:

$$
R E V_{i, t}=\left(P_{i, t}+\Omega_{i, t}\right) \cdot D_{i, t}
$$

where $P_{i, t}$ is the typical residential marginal price for an acre-foot of water, and $\Omega_{i, t}$ is an exogenous unobserved source of marginal revenues arising from deviations of the true marginal price from $P_{i, t}$ for some sales. Both $\chi_{i, t}$ and $\Omega_{i, t}$ are known by the managers of city $i$ when choosing the price for fiscal year $t$, but the econometrician observes them only in distribution.

\subsection{Objective Function}

A hybrid objective function is ascribed to the municipal manager as a simple empirical formulation of ideas regarding the behavior of municipally owned firms that have been developed in the regulation literature (Peltzman (1971), Baron and Myerson (1982)). Each municipally owned and operated utility is assumed to behave much like a privately owned firm. The residents of the municipality comprise its de facto shareholders and receive dividends in the form of lower taxes and/or increased municipal services. Municipal managers have an incentive to reduce tax burdens by earning profits from the provision of goods and services; doing so increases the value of the city's "stock," making more likely the continuation of its management's employment. At the same time, however, every "shareholder" of the municipality also consumes its water output. The managers of the municipality, who ultimately report to the constituency via the mayor or an elected city council, realize this. In pursuit of maintained employment, they distribute lower prices to the segments of the constituency that they believe to be instrumental in holding office, with the net effect being "a downward bias in government enterprise prices" (Peltzman (1971, p.113)). For practical purposes, I assume that these price discounts are given to consumers of water, while they are financed by taxpayers and consumers of other municipal services. The same 
individuals, of course, play both roles depending on the time of day and the month of the year. This abstraction allows a municipal manager's deviation from efficient pricing (i.e., from equally weighting benefits to taxpayers and water consumers in his preference function) to be quantified, which is sufficient for the current exercise.

A more detailed model of municipal manager behavior than is permitted by the data is required to explain why a municipal manager would choose to deviate from efficient pricing and impose a deadweight loss on his constituency. Empirical evidence suggests that managers might use property and sales taxes, as well as a broad array of user-fees, to substitute for relatively regressive water bills in the acquisition of municipal revenues, allowing the municipal government (which operates with a limited set of tools) to achieve some modicum of income redistribution (Timmins (1999a)). Another possibility is that municipal residents simply react more strongly to water bills (i.e., monthly charges for a well-defined commodity) than to tax bills (i.e., annual charges for a loosely defined set of public goods) at the ballot box. Political economy concerns would then dictate discounting water prices at the expense of higher tax bills.

Summarizing this argument along with Subsections 2.1-2.4, the municipality is assumed to behave as a cost-minimizer in the production of water, conditional upon its choice of price. In determining that price, the municipal management values some combination of (i) profits from operations, which are assumed to offset taxpayers' burdens, (ii) the welfare of its constituents, measured in terms of their surplus from water consumption, and (iii) being able to supply water at a low cost to those constituents in the future. These arguments imply that municipality $i$ receives payoffs from operations in fiscal year $t\left(\Pi_{i, t}\right)$ that are a function of its choice of marginal price $\left(P_{i, t}\right)$, its lift-height at the start of the year $\left(h_{i, t}\right)$, a vector of exogenous municipal characteristics $\left(S_{i, t}, I N C_{i, t}, c_{i}, \mu_{i}^{R}, \operatorname{rech}_{i, t}, \chi_{i, t}, \Omega_{i, t}\right)$, a vector of i.i.d. sources of uncertainty $\left(\varepsilon_{i, t}^{g}, \varepsilon_{i, t}^{R}, \varepsilon_{i, t}^{d}\right)$, and a vector of parameters (i.e., $\delta$ 's, $\alpha$ 's, and a convex-combination weighting parameter, $v$, that is common to all municipalities):

$$
\Pi_{i, t}=\nu \cdot C S_{i, t}+(1-\nu) \cdot\left[\left(P_{i, t}+\Omega_{i, t}\right) \cdot D_{i, t}-C_{i, t}^{g}-\left(c_{i}+\chi_{i, t}\right) \cdot D_{i, t}\right] .
$$

$C S_{i, t}$ measures aggregate consumer surplus from water consumption (net of payments for water):

$$
C S_{i, t}=\int_{P_{i, t}}^{\infty} e^{\delta_{0}+\text { citdum }^{\prime} \delta_{0, i}-\delta_{1} y+\delta_{2} I N C_{i, t}-\delta_{3} \mu_{i}^{R}+\delta_{4} S_{i, t}-\delta_{3} \varepsilon_{i, t}^{R}+\varepsilon_{i, t}^{d}} d y .
$$

This stochastic objective function is easily interpreted in the context of models typically used to study regulatory processes. In particular, it flexibly models the price-setting decision of a regulator who possesses perfect information regarding the regulated firm. Given the small size of the government offices under consideration, this is a realistic assumption. Moreover, the full range of objectives typically attributed to such a regulator (Baron (1989)) are nested within this 
hypothesized objective function. A net-surplus maximizing regulator, for example, would exhibit $v=1 / 2$, while a regulator seeking to maximize utility returns would be evidenced by $v=0$. A regulator wishing to maximize consumer welfare at the expense of taxpayers would be described by $v=1$, which would lead to a flat-rate price (i.e., $P_{i, t}=0$ ) regardless of costs. A regulator pricing to recoup average costs under the cost structure outlined above would be evidenced by some $v \in(0,1)$.

I attribute to the municipal management an infinite time horizon, which is appropriate given that there is no foreseeable time at which its groundwater rights will be revoked and because exit is not a concern. The role of political timetables in shortening this horizon is being considered in current research. Management is assumed to discount future payoffs from groundwater provision with a discount factor $\beta \in[0,1]$. Industry evidence supports the assumption of no relevant upper bound on lift-height; i.e., it is believed that before the aquifer would be exhausted, extraction would become so costly as to merit a switch to a substitute water source (Diringer (1991)). Given some backstop technology, this implies the existence of a steady-state lift-height, eliminating the need for further transversality conditions. Note that, in the simulations described below, predicted costs over the next fifty years do not approach the level required to induce a switch to an alternative water source.

Under these assumptions, the municipal management chooses its price path to maximize the expected present discounted value of its payoffs from groundwater provision:

$$
\max _{\left[P_{i, t} \geq 0\right]} E_{t_{0}}\left[\sum_{t=t_{0}}^{\infty} \beta^{t-t_{0}} \Pi_{i, t}\right]
$$

subject to the law of motion for $h_{i, t}$.

In order to estimate this model, distributional assumptions must be made for the unobserved (to the econometrician) components of marginal costs $\left(\chi_{i, t}\right)$ and marginal revenues $\left(\Omega_{i, t}\right)$. To facilitate estimation, the two unobserved components are combined into a single variable, unobserved net marginal revenues (i.e., $\xi_{i, t}=\Omega_{i, t}-\chi_{i, t}$ ), which is parameterized as a first-order Markov process:

$$
\xi_{i, t+1}=\rho_{0}+\rho_{1} \xi_{i, t}+\varepsilon_{i, t}^{\xi}, \quad \varepsilon_{i, t}^{\xi} \sim \text { i.i.d. } N\left(0, \sigma_{\xi}^{2}\right) .
$$

Cities with high unobserved costs (i.e., from inefficient pumps or leaky pipes) will tend to exhibit low unobserved net marginal revenues over time; the opposite would be true of cities that earn many unobserved revenues (e.g., from repeated special sales to a particular industrial user). 
A number of additional simplifications can be made in this dynamic objective function:

$$
\begin{aligned}
& X_{i, t}=\left[S_{i, t}, I N C_{i, t}, \mu_{i}^{R}, c_{i}, A V G_{i, t}, \text { rech }_{i, t}, R_{i, t-1}\right], \\
& \bar{\varepsilon}_{i, t}^{1}=\left(\begin{array}{c}
\varepsilon_{i, t}^{d} \\
\varepsilon_{i, t}^{g} \\
\varepsilon_{i, t}^{R}
\end{array}\right) \sim \text { i.i.d. } N\left[\left(\begin{array}{l}
0 \\
0 \\
0
\end{array}\right),\left(\begin{array}{ccc}
\sigma_{d}^{2} & 0 & 0 \\
0 & \sigma_{g}^{2} & 0 \\
0 & 0 & \sigma_{R, i}^{2}
\end{array}\right)\right], \\
& \bar{\varepsilon}_{i, t}^{2}=\left(\begin{array}{c}
\varepsilon_{i, t}^{\xi} \\
\varepsilon_{i, t}^{h}
\end{array}\right) \sim \text { i.i.d. } N\left[\left(\begin{array}{l}
0 \\
0
\end{array}\right),\left(\begin{array}{cc}
\sigma_{\xi}^{2} & 0 \\
0 & \sigma_{h}^{2}
\end{array}\right)\right], \\
& \theta_{1}=[\bar{\delta}, \bar{\alpha}, \bar{\gamma}, \bar{\rho}, \bar{\sigma}, \nu], \quad \pi_{i, t}=P_{i, t} D_{i, t}-C_{i, t}^{g}-c_{i} D_{i, t} .
\end{aligned}
$$

The municipality's problem can then be expressed with the following Bellman functional form:

$$
\begin{aligned}
V\left(h_{i, t},\right. & \left.\xi_{i, t} \mid X_{i, t} ; \theta_{1}\right) \\
= & \max _{\left[P_{i, t} \geq 0\right]} E_{\bar{\varepsilon}_{i, t}^{1}}\left[\nu \cdot C S\left(P_{i, t}, X_{i, t}, \bar{\varepsilon}_{i, t}^{1} ; \theta_{1}\right)+(1-\nu)\right. \\
& \cdot\left[\pi\left(P_{i, t}, h_{i, t}, X_{i, t}, \xi_{i, t}, \bar{\varepsilon}_{i, t}^{1} ; \theta_{1}\right)+\xi_{i, t} D\left(P_{i, t}, X_{i, t}, \bar{\varepsilon}_{i, t}^{1} ; \theta_{1}\right)\right] \\
+ & \left.\beta E_{\bar{\varepsilon}_{i, t}^{2}}\left[V\left(h_{i, t+1}, \xi_{i, t+1} \mid X_{i, t} ; \theta_{1}\right) \mid P_{i, t}, h_{i, t}, \xi_{i, t}, X_{i, t} ; \theta_{1}\right]\right] \text { subject to } \\
h_{i, t+1}=\gamma_{0} h_{i, t}+\gamma_{1}+\operatorname{citdum}^{\prime} \gamma_{1, i}+\gamma_{2} D_{i, t} & \quad-\gamma_{2, A} \operatorname{rech}_{i, t}-\gamma_{3} R_{i, t-1}-\gamma_{4} A V G_{i, t}+\varepsilon_{i, t}^{h}, \\
\xi_{i, t+1}= & \rho_{0}+\rho_{1} \xi_{i, t}+\varepsilon_{i, t}^{\xi} .
\end{aligned}
$$

See footnote 6 for a discussion of the conditioning role played by $X_{i, t}$ in this equation. Stokey and Lucas (1989) outlines a proof of the existence of a contraction mapping for this functional equation that results in a unique representation of the value function. It also guarantees the existence of a nonempty, compactvalued, and upper hemi-continuous policy function that defines $P_{i, t}$ as a function of $h_{i, t}$ and $\xi_{i, t}$, conditional upon $X_{i, t}$ and the parameter vector, $\theta_{1}$.

\subsection{Identification Assumptions}

Without a few additional assumptions, the behavioral parameters of this Markov decision process are not identified (Rust (1994, pp.127-131)). In particular, conditional upon observed municipal characteristics and realizations of lift-height, it is still impossible to differentiate between the effects of behavioral heterogeneity, unobserved components of costs and revenues, and heterogeneous expectations about the future, vis-à-vis their respective impacts on observed pricing decisions. The first of these potential explanations can be ruled-out by the 
assumption that all municipalities exhibit the same value of $v$ and dynamically maximize payoffs from groundwater provision, while the second explanation is the source of variation that identifies the parameters of the $\xi_{i, t}$ process. In order to rule-out the third potential explanation, it must be assumed that, conditional upon observed municipal characteristics, (i) all cities have homogeneous expectations of the future availability of groundwater substitutes and that these expectations are constant over time, and (ii) all cities discount future payoffs according to the same discount factor, $\beta$. Given the cities' similar size and geographic location, the second assumption is realistic. The value of $\beta$ that is assumed in the estimation process $(\beta=0.95)$ implicitly captures the homogeneous expectations described in (i). Any value of $\beta$, however, could have been used, depending upon the econometrician's beliefs about municipalities' expectations. Sensitivity analyses were performed to determine the robustness of the conclusions to alternative values of $\beta$.

\section{DATA}

Incorporating the dynamics of owned water stock management into an analysis of municipal water pricing introduces significant data requirements that go well beyond those of static empirical water utility analyses (Mann and Mikesell (1976), Feigenbaum and Teeples (1983), Teeples and Glyer (1987)) and calibrated resource management studies (Burt (1964a, 1964b, and 1967), Brown and Deacon (1972), Gisser and Sanchez (1980), Allen and Gisser (1984), Brill and Burness (1994), Knapp and Olsen (1995)). In particular, it necessitates coordinated production, aquifer, climate, and demographic data on numerous municipalities over time. From a number of data sources, I have constructed such a panel, which describes thirteen cities in California's southern San Joaquin Valley between 1970 and 1993. (See list in Table I.) The variables in this panel fall into the following categories: (i) characteristic data, which describe the exogenous market conditions under which municipal managers operate, (ii) economic decision data, which describe the endogenously determined policy options pursued by municipal managers and the resulting market equilibria, and (iii) environmental data, which describe the complex hydrogeological and climatic forces that influence municipal managers' decisions. Table III summarizes the full panel.

The characteristic data consist of variables that describe the markets served by municipal utilities but that are assumed (i) to evolve exogenously from municipal managers' decisions, and (ii) to be treated myopically by municipal managers. ${ }^{6}$

\footnotetext{
${ }^{6}$ In order to reduce the dimensionality of the state space to a computationally feasible level, I assume that municipal managers treat the realizations of these characteristic variables at each point in time as indicative of their future values. Unlike the aquifer stock and the unobserved (to the econometrician) components of costs and revenues, these variables, therefore, do not enter into the state vector. An alternative approach that would yield the same computational benefit would be to assume perfect foresight on the part of municipal managers. Given the slow movement in these variables over time (note that they do vary significantly in the cross-sectional dimension), the choice of simplifying assumption is not likely to have a strong effect on the results.
} 
TABLE III

Summary Statistics, Full Data Panel ( $n=195$, CONStant 1982-84 DOllars)

\begin{tabular}{lcccc}
\hline \hline Variable & Mean & Std. Deviation & Minimum & Maximum \\
\hline Avg. Household Demand (af) & 1.10 & 0.31 & 0.31 & 1.99 \\
Total Urban Demand (af) & 7777 & 18838 & 678 & 118665 \\
Number of Households & 7181 & 15580 & 546 & 99049 \\
Real Median Virtual Household Income & 19662.64 & 3177.93 & 12430.91 & 30813.95 \\
Annual Precipitation (1") & 9.7 & 3.9 & 3.0 & 23.6 \\
Aquifer Lift-Height (ft) & 60.1 & 51.5 & 2.8 & 236.6 \\
Avg. Aquifer Height Difference (AVG) & 3.3 & 10.2 & -17.6 & 29.5 \\
Marginal Price (\$/af) & 45.87 & 56.80 & 0.00 & 303.40 \\
Artificial Recharge (af) & 1676 & 7295 & 0 & 59578 \\
\hline
\end{tabular}

Among these variables are key components of municipal demand, including the size of the urban population and the income of urban residents. From the California State Department of Finance, I have acquired annual population estimates for each of the thirteen municipalities in the panel (California Department of Finance (1970-1993)), and from decennial US Census data on household incomes, in combination with annual California Department of Finance statistics on per-capita incomes, I have constructed imputed annual median household incomes by city.

Economic decision data are composed of those variables that describe the decisions made by municipal water utility managers and urban consumers of water, as well as the market equilibria that those decisions, in conjunction with characteristic and environmental variables, induce. The most important of these data describe the residential rate structures set by municipalities. In particular, data on total revenues, service charges, and block-rate pricing structures, which are obtained from the California State Controller's Office: Municipal Income and Expense Statements, are used to construct approximate two-part municipal pricing measures that are observed by the econometrician with error. ${ }^{7}$ Aggregate municipal demand is sporadically observed in State Controller records, which are supplemented by California Department of Water Resources databases and detailed pumping records that have been obtained directly from municipal water

\footnotetext{
${ }^{7}$ Specifically, the price paid for the marginal unit of water consumed by a typical household $\left(P_{i, t}\right)$ is taken as the slope of the second segment of the municipality's two-part total revenue function. The first leg of that function is drawn by noting the observed values for (i) the monthly household service charge for connection to the municipal system $\left(\psi_{i, t}\right)$, (ii) the quantity of "free" water that accompanies the payment of that charge $\left(w_{i, t}\right)$, and (iii) the number of households in the municipality $\left(S_{i, t}\right)$, all of whom are assumed to hookup to the system. A linear spline is then used to approximate the remainder of the total revenue function, knowing the value of that function at $S_{i, t} w_{i, t}$ and $D_{i, t}$ (i.e., the total quantity of water sold in the municipality). The slope of that spline approximates $P_{i, t}$.

In order for this method to generate an unbiased measure of $P_{i, t}$, the ratio of the fixed service charge to the quantity of free water that accompanies the payment of that charge, $\left(\psi_{i, t} / w_{i, t}\right)$, must be the same across connection types (i.e., governmental, industrial, and commercial). The possibility that $\left(\psi_{i, t} / w_{i, t}\right)$ differs by connection type, leading to error in $P_{i, t}$ appears explicitly in the structural model in the form of the unobserved component of marginal revenues, $\Omega_{i, l}$.
} 
utility management. Other economic decision variables include figures describing operating expenditures. The State Controller's records decompose the variable costs of water utility operation to a level commensurate with the model outlined above. In particular, pumping costs, which comprise over $32 \%$ of all variable expenditures in water production, describe the total payments made in lifting an observed quantity of groundwater a known distance to the surface, and (after much validation) are assumed to be observed without error. Data describing the costs of water treatment, pressurization, transmission and distribution, as well as general administrative, sales, and customer account maintenance costs, detail the total expenditures made in each of these activities as raw water is processed and delivered to consumers. Along with the pumping cost and rate structure data, these figures allow for the direct measurement of variable profits (i.e, a key component of the municipal manager's hypothesized objective function), but are also a significant source of measurement error in the model. ${ }^{8}$ Finally, data describing the costs of new capital and network maintenance (i.e., fixed costs), while sometimes observed in Municipal Income and Expense Statements, are of very poor quality. This is not surprising given the potential for measurement error associated with municipal accounting practices to compound the usual difficulties encountered in valuing capital stocks and measuring depreciation. In response, it is assumed that the fixed service charge is set to exactly recoup the fixed costs of water provision, i.e., as in the first half of an optimal two-part tariff. While this is certainly a debatable assumption, cursory statistical evidence indicates that cities with characteristics associated with high fixed costs of water provision (e.g., low population density) do assess greater service charges.

Finally, environmental data describe the climatological and hydrogeological factors that make the study of a renewable aquifer stock unique. From California's Department of Water Resources, San Joaquin District Office, I have obtained detailed hydrogeological panel data that characterize the San Joaquin Valley aquifer, the only source of raw water for the thirteen cities in the data panel, at the level of a six square-mile grid between 1970 and 1993. By integrating these data with municipal altitude data, I am able to determine a city's lift-height each year, which is a convenient measure of its groundwater stock and an important determinant of its variable costs. These data are also used to determine how each municipality might be affected by the extraction decisions of its neighbors, allowing any "common-pool" aspects of the aquifer to be handled explicitly, although without accounting for strategic interactions between neighbors (allowing for such interactions would necessitate the introduction of a Markov Perfect Nash Equilibrium, making estimation computationally impractical). Monthly rainfall figures for several locations across the Valley were obtained from the National Climatic Data Center and are used both to identify demand parameters and to determine a component of the Markov process that drives

\footnotetext{
${ }^{8}$ Nonuniform accounting standards across municipalities imply that expenditures for the same nonpumping activity in different cities might not be included in any reported cost category. The empirical model accounts for this source of measurement error with the introduction of the structural error term, $\chi_{i, t}$.
} 
groundwater stock. Finally, data describing the quantity of water artificially recharged to the aquifer stock each year by each city were obtained directly from municipal managers. Given the long-run nature of the contracts for federal or state surface water deliveries (which comprised the only source of water available for artificial recharge) and recognizing the inconsistent delivery of those supplies over the last twenty-five years, artificial recharge is included in the model as an exogenous environmental variable (similar to rainfall) that only affects lift-height.

\section{TWO-STAGE ESTIMATION ALGORITHM}

A nested maximum likelihood estimation procedure is used to recover the parameters underlying the municipality's dynamic payoff-maximization problem. That procedure (i) uses a continuous state-continuous (but constrained) control version of a numerical fixed-point algorithm to find the solution to the municipal manager's dynamic programming problem, (ii) employs that solution in deriving the likelihood function, and (iii) nests those likelihood function evaluations in a quasi-Newton hill-climbing algorithm. This method is adopted in lieu of Euler equation techniques because of the high incidence of constrained pricing decisions observed in the data. In particular, municipal managers charge a marginal price of zero in nearly half of all observations (see Table II), which precludes the derivation of Euler equations by simple offsetting variations. Techniques that have been developed to mitigate such difficulties (Pakes (1994)) would still require throwing-out many of the constrained observations, including all of the data describing six of the thirteen cities in the panel that never charge a positive marginal price.

The following discussion describes the derivation of the conditional likelihood function that is used to estimate the parameters of the municipal manager's dynamic objective function. The full likelihood function measures the probability of realizing an observed vector of data, $\left[P_{i, t}, h_{i, t}, X_{i, t}, D_{i, t}\right]$, as well as a vector of unobserved net marginal revenues, $\xi_{i, t}$, as a function of a parameter vector, $\Theta$. $X_{i, t}$ is presumed to evolve according to a process determined by the parameter vector, $\theta_{2}$ (i.e., $\Theta / \theta_{1}$ ). With some vector notation, ${ }^{9}$ and temporarily treating $\xi_{i, t}$ as if it were observed data, the relevant probability density can be written in its most primitive form as

$$
f(\bar{h}, \bar{P}, \bar{D}, \bar{\xi}, \bar{X} ; \Theta) \text {. }
$$

Conditioning upon the exogenous states, $X_{i, t}$, and assuming that the conditional joint density of $P_{i, t}, h_{i, t}, D_{i, t}$, and $\xi_{i, t} \forall i, t$ is independent across cities, this density can be rewritten as

$$
f\left(\bar{h}, \bar{P}, \bar{D}, \bar{\xi} \mid \bar{X} ; \theta_{1}\right)=\prod_{i=1}^{13} f_{i}\left(\bar{h}_{i}, \bar{P}_{i}, \bar{D}_{i}, \bar{\xi}_{i} \mid \bar{X}_{i} ; \theta_{1}\right) .
$$

\footnotetext{
${ }^{9}$ Given panel data $A_{i, t}, \bar{A}$ refers to the $[(T \cdot I) \times 1]$ stacked vector considered over all $i$ and $t . \bar{A}_{i}$ refers to the $[T \times 1]$ vector considered over $t$, conditional upon $i$, and $\bar{A}_{t}$ refers to the $[I \times 1]$ vector considered over $i$, conditional upon $t$.
} 
Next, recall four useful results from the Markov decision process outlined in Section 2: (i) $D_{i, t}$ is a function of only $P_{i, t}, X_{i, t}$, a stochastic term, and $\theta_{1}$; (ii) the solution to the functional equation corresponding to the municipal manager's dynamic programming problem defines price as a function of only $h_{i, t}, X_{i, t}, \xi_{i, t}$, and $\theta_{1}$ (i.e., $h_{i, t}$ summarizes the impact of all past choices on the current choice of price), (iii) $h_{i, t}$ is a function of only $h_{i, t-1}, D_{i, t-1}, X_{i, t-1}, \varepsilon_{i, t-1}^{h}$, and $\theta_{1}$, and (iv) $\xi_{i, t}$ is a function of only $\xi_{i, t-1}, \varepsilon_{i, t-1}^{\xi}$, and $\theta_{1}$. With these four results, each term on the right-hand side of (4.2) can then be factored according to an iterative procedure, ${ }^{10}$ yielding

$$
\begin{aligned}
f\left(\bar{h}_{i}, \bar{P}_{i}, \bar{D}_{i}, \bar{\xi}_{i} \mid \bar{X}_{i} ; \theta_{1}\right) & \\
=\left[\prod _ { t = 1 } ^ { T _ { 1 } - 1 } f _ { D } \left(D_{i, t+1} \mid\right.\right. & \left.P_{i, t+1}, X_{i, t+1} ; \theta_{1}\right) \cdot f_{P}\left(P_{i, t+1} \mid h_{i, t+1}, X_{i, t+1}, \xi_{i, t} ; \theta_{1}\right) \\
& \left.\cdot f_{h}\left(h_{i, t+1} \mid h_{i, t}, D_{i, t}, X_{i, t} ; \theta_{1}\right) \cdot f_{\xi}\left(\xi_{i, t} \mid \xi_{i, t-1} ; \theta_{1}\right)\right] \\
& \quad f\left(P_{i, 1}, h_{i, 1}, D_{i, 1} \mid X_{i, 1}, X_{i, 0} ; \theta_{1}\right)
\end{aligned}
$$

where $\xi_{i, 1}$ is distributed conditional upon $\xi_{i, 0}$, a parameter to be estimated for each city.

Each of the probabilities in this expression can be calculated as follows. First, given the distributional assumptions outlined in Section 2, conditional probability densities for $D$ and $h$ are calculated by a change-of-variables. The specification of the dynamic programming problem in (2.5.6) and the invertibility of the policy function over $\xi_{i, t}$, given $\xi_{i, t-1}$ and $\theta_{1}$, suggest an iterative process for deriving the conditional probabilities of $P$ and $\xi$. In particular, for each realization of $X_{i, t}$, the conditional policy function, $P\left(h_{i, t}, \xi_{i, t} \mid X_{i, t} ; \theta_{1}\right)$ is calculated at every point in $[h, \xi]$ space via a combination of value and policy function iteration for some initial parameter guess $\theta_{1}^{0}$ (Judd (1998, Ch. 12)). In every case, the conditional value function is monotonically decreasing in lift-height and monotonically increasing in unobserved net marginal revenues. The conditional policy function, conversely, is monotonically increasing in lift-height and weakly monotonically decreasing in unobserved net marginal revenues. Next, using the distribution ascribed to the unobserved component of net marginal revenues $\left(\xi_{i, t}=\rho_{0}+\rho_{1} \xi_{i, t-1}+\varepsilon_{i, t}^{\xi}, \varepsilon_{i, t}^{\xi} \sim\right.$ i.i.d. $\left.N\left(0, \sigma_{\xi}^{2}\right)\right)$ and conditioning upon an observed value of $h_{i, t}$, the conditional policy function is inverted to arrive at a conditional probability density for $P_{i, t}$ :

$$
f_{p}\left(P_{i, t} \mid h_{i, t}, X_{i, t}, \xi_{i, t-1} ; \theta_{1}^{0}\right)=\left[f_{P \mid P=0}\right]^{\lambda_{i, t}}\left[f_{P \mid P>0}\right]^{1-\lambda_{i, t}}
$$

${ }^{10}$ First, the conditional density of demand in year $T$ for city $i$ is separated from the joint density of city $i$ 's data. The conditional density of city $i$ 's price in year $T$ is then separated from the remaining joint density. A similar process is conducted for lift-height in year $T$, and $\xi$ in year $T-1$. The resulting univariate conditional probabilities are simplified with results (i)-(iv) described above, and the process is duplicated for year $T-1$ (i.e., year $T-2$ for $\xi$ ). Repeating this procedure $T-1$ times for each city, and conditioning on the joint distribution of $P_{i, 1}, h_{i, 1}$, and $D_{i, 1}$ and on the estimated parameters $\xi_{i, 0}$ yields the expression in (4.3). 


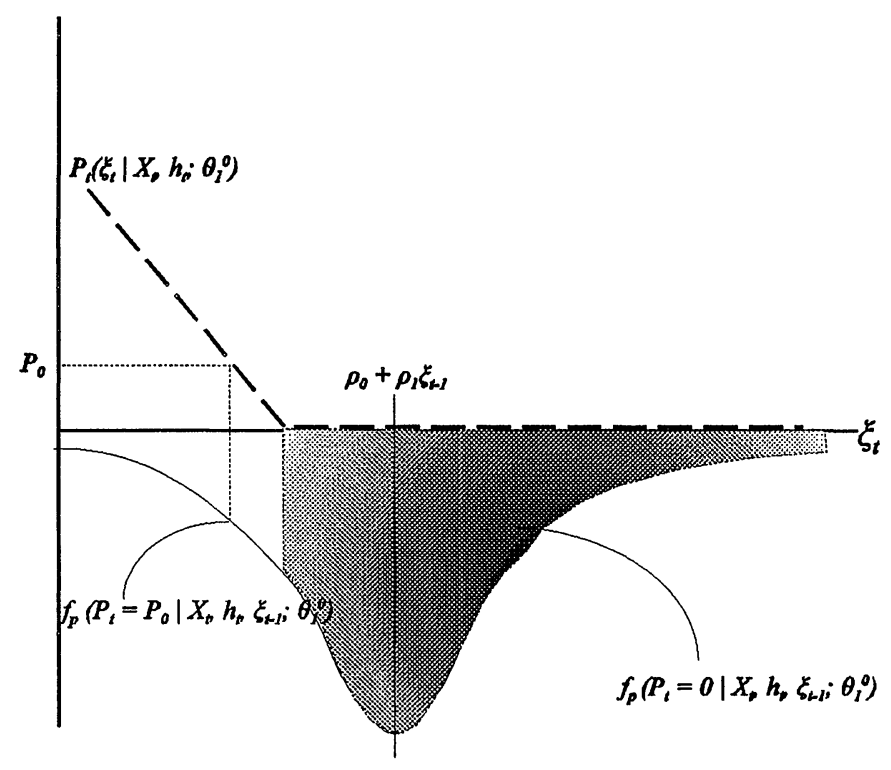

FIGURE 2.

where $\lambda_{i, t}=1$ if $P_{i, t}=0, \lambda_{i, t}=0$ if $P_{i, t}>0$, and

$$
f_{P \mid P=0}=1-\Phi\left(\frac{\xi_{i, t}^{*}-\mu_{\xi}}{\sigma_{\xi}}\right), \quad f_{P \mid P>0}=\frac{\phi\left(\frac{g^{-1}\left(P_{i, t}\right)-\mu_{\xi}}{\sigma_{\xi}}\right)}{\Phi\left(\frac{\xi_{i, t}^{*}-\mu_{\xi}}{\sigma_{\xi}}\right)} \cdot\left\|\frac{\partial g^{-1}}{\partial P_{i, t}}\right\|
$$

(see Figure 2), $\xi_{i, t}^{*}$ denotes the value of $\xi$ where, conditional upon observed $h_{i, t}$, the nonnegativity constraint on price begins to bind; i.e., $P_{i, t}=g\left(\xi_{i, t}\right)$ for all $\xi_{i, t}<$ $\xi_{i, t}^{*}$. Finally, given the conditional policy function, conditioning upon observed $h_{i, t}$ and the parameter vector $\theta_{1}^{0}$, and given some $\xi_{i, t-1}$ calculated in the previous iteration (or given the parameter $\xi_{i, 0}^{0}$ if in the first iteration), observed $P_{i, t}>0$ determines $\xi_{i, t}$. This value of $\xi_{i, t}$ then becomes the basis for the calculation of the probability of observing $P_{i, t+1}$ in the next iteration, given $\theta_{1}^{0}$ and observed $h_{i, t+1}$.

For cities charging $P_{i, t}=0$ (recall that this applies to approximately one-half of the sample), calculating the likelihood function is more complicated. In particular, a unique value of $\xi_{i, t}$ cannot be recovered by inverting the policy function; i.e., the only available information is that $\xi_{i, t}$ lies in the flat region of the policy function. Instead, the expectation of the entire likelihood expression for these cities must be calculated with respect to the distribution of the Markov chain of $\xi$ 's. Specifically, for the six cities in the panel that always charge a marginal price of zero, a Monte Carlo simulation approach is used to calculate their expected contribution to the likelihood function. First, conditional policy functions are calculated for each of these cities in every year, over every possible value of 
$\xi$. A sequence of $\xi$ 's are then simulated for each of these cities, conditional upon $P_{i, t}=0$ given the conditional policy function (i.e., random draws determining the increment to $\xi$ each period come from truncated normal distributions, with the truncation point being determined in period $t$ by $\xi_{i, t-1}$ and the value of $\xi_{i, t}^{*}$ where the policy function becomes constrained in period $t$ ). The likelihood function is then calculated for each city for each simulated sequence of $\xi$ 's. $f_{p}\left(P_{i, t} \mid h_{i, t}, X_{i, t}, \xi_{i, t-1} ; \theta_{1}^{0}\right)$ is still given by the integral expression in (4.5) when $P=0$, but $\xi_{i, t-1}$, which enters that expression through $\mu_{\xi}$, comes from a simulation draw of $\varepsilon_{i, t}^{\xi}$ and the previously simulated value of $\xi_{i, t-2}$. As in any Monte Carlo integration, the probability of observing the particular sequence of random draws (i.e., the sequence of $f_{\xi}\left(\xi_{i, t} \mid \xi_{i, t-1}, \theta_{1}^{0}\right)$ 's), does not appear explicitly. The likelihood is calculated for each of 1,000 simulated sequences of $\xi$ 's, making simulation error negligible. The expectation of city $i$ 's contribution to the likelihood function is found by taking the average of these 1,000 simulated likelihoods.

The conditional likelihood of observing all the data given the parameter vector $\left[\theta_{1}^{0}, \xi_{i, 0}^{0}\right]$ can be written:

$$
\begin{array}{r}
L\left(\bar{h}, \bar{P}, \bar{D}, \bar{\xi} \mid \bar{X}, \bar{P}_{1}, \bar{h}_{1} ; \theta_{1}^{0}, \bar{\xi}_{0}^{0}\right) \\
=\left[\prod_{P>0}^{T_{i}-1} \prod_{t=1} f_{D}\left(D_{i, t+1} \mid P_{i, t+1}, X_{i, t+1} ; \theta_{1}^{0}\right) f_{p}\left(P_{i, t+1} \mid h_{i, t+1}, X_{i, t+1}, \xi_{i, t} ; \theta_{1}^{0}\right)\right. \\
\left.\cdot f_{h}\left(h_{i, t+1} \mid h_{i, t}, D_{i, t}, X_{i, t} ; \theta_{1}^{0}\right) \cdot f_{\xi}\left(\xi_{i, t} \mid \xi_{i, t-1} ; \theta_{1}^{0}\right)\right] \\
\cdot \prod_{P=0} E\left[\prod_{t=1}^{T_{i}-1} f_{D}\left(D_{i, t+1} \mid P_{i, t+1}, X_{i, t+1} ; \theta_{1}^{0}\right) \cdot f_{p}\left(P_{i, t+1} \mid h_{i, t+1}, X_{i, t+1}, \xi_{i, t} ; \theta_{1}^{0}\right)\right. \\
\left.\cdot f_{h}\left(h_{i, t+1} \mid h_{i, t}, D_{i, t}, X_{i, t} ; \theta_{1}^{0}\right)\right] .
\end{array}
$$

New values of $\theta_{1}^{1}$ and $\xi_{i, 0}^{1}$ are determined so as to increase $L$, and estimates of $\theta_{1}$ and $\xi_{i, 0}$ are those values that maximize this expression. These estimates are both consistent and asymptotically efficient as $T \rightarrow \infty .^{11}$

This algorithm would be prohibitively time-consuming given the sixty-eight parameters that comprise $\theta_{1}$. As such, I employ a two-step estimation routine whereby all parameters in $\theta_{1}$ except $v, \rho_{0}, \rho_{1}, \sigma_{\xi}$, and $\xi_{i, 0}, i=1,2, \ldots, 13$, are estimated using the full data panel in a first-stage instrumental variables procedure that does not require the solution to a dynamic program. I then use these estimated parameter values in the dynamic maximum likelihood estimation of the remaining parameters as if they were known with certainty. Observations not satisfying dynamic data requirements are dropped in this second stage, leaving

\footnotetext{
${ }^{11}$ The term $\prod_{i} f_{i}\left(P_{i, 1}, h_{i, 1}, D_{i, 1}, \mid X_{i, 1}, X_{i, 0} ; \theta_{1}\right)$, upon which this likelihood function is conditioned, becomes inconsequential in identifying $\theta_{1}$ and $\xi_{i, 0}$ as the data grow in the time dimension. Moreover, the term $f_{X}\left(X ; \theta_{2}\right)$ has no bearing on the estimation of $\theta_{1}$ and $\xi_{i, 0} . f_{X}\left(X ; \theta_{2}\right)$ can thus be excluded from the conditional likelihood function as well.
} 
TABLE IV

First-Stage Parameter Estimates ${ }^{a}$

(A = Demand, B = LifT-Height Law of Motion,

$\mathrm{C}=$ PumPing COSTS, $\mathrm{D}=$ NONPUMPING COSTS)

\begin{tabular}{lcc}
\hline \hline Variable & Coefficient & $\begin{array}{c}\text { Standard } \\
\text { Error }\end{array}$ \\
\hline A: Constant & 7.27 & 0.17 \\
Price & $7.49 \times 10^{-3}$ & $2.97 \times 10^{-3}$ \\
Virtual Income & $4.03 \times 10^{-5}$ & $9.74 \times 10^{-6}$ \\
Rainfall & $1.20 \times 10^{-4}$ & $5.37 \times 10^{-5}$ \\
Connections & $1.70 \times 10^{-4}$ & $1.43 \times 10^{-5}$ \\
B: & 0.97 & $1.32 \times 10^{-2}$ \\
Lift-Height $(-1)$ & 0.80 & 2.55 \\
Constant & $6.35 \times 10^{-4}$ & $2.05 \times 10^{-4}$ \\
Extraction & $4.73 \times 10^{-4}$ & $2.28 \times 10^{-4}$ \\
Artificial Recharge & 0.01 & $1.03 \times 10^{-3}$ \\
Rainfall $(-1)$ & 0.77 & 0.18 \\
AVG & -1.66 & 0.89 \\
C: & 1.09 & 0.18 \\
Constant & 1.18 & $7.08 \times 10^{-2}$ \\
Ext-Height & 80.02 & 6.21 \\
D: & -15.37 & 11.60 \\
$c_{0}$ & 110.83 & 22.75 \\
$c_{\text {Clovis }}$ & -32.24 & 9.06 \\
$c_{\text {Dinuba }}$ & 24.19 & 13.88 \\
$c_{\text {Exeter }}$ & -17.59 & 12.45 \\
$c_{\text {Firebaugh }}$ & -18.58 & 7.73 \\
$c_{\text {Kerman }}$ & 58.75 & 25.36 \\
$c_{\text {Madera }}$ & -14.73 & 10.75 \\
$c_{\text {Mendota }}$ & -27.00 & 16.20 \\
$c_{\text {Sanger }}$ & & \\
$c_{\text {Shafter }}$ & & \\
\hline
\end{tabular}

${ }^{\text {a Sample size }}=195$. GMM objective function value $=0.13$ yielding a chi-squared instrument quality test statistic of 25.64 (i.e., with 15 degrees of freedom). Standard errors are heteroskedasticconsistent, and municipal heterogeneity terms are not shown.

a total of one-hundred-sixteen observations. The standard errors of the secondstage estimates are then calculated while accounting for the error introduced by the first-stage parameter estimates.

This routine was applied to the thirteen cities in the data panel. The point estimates and standard errors of the parameters found in the first-stage regressions are reported in Table IV. These estimates were recovered from a joint instrumental variables estimation of the demand, pumping cost, lift-height law of motion, and observed nonpumping marginal cost functions. Extraction, which appears in the pumping cost and lift-height equations, was treated as endogenous. This variable may be correlated with excluded variables like temperature, which might also affect the cost of pumping or the behavior of lift-height. Virtual income and the number of service connections in each city were used as instruments for extraction. Another concern was that serial autocorrelation in the error terms of 
TABLE V

Nested Fixed-Point Estimation Algorithm Parameter ESTIMATES $\beta=0.95, n=116$, LOG-LIKELIHOOD $=-2209.16$

\begin{tabular}{lrc}
\hline \hline Parameter & Estimate & Standard Error \\
\hline$v$ & 0.73 & $5.44 \times 10^{-3}$ \\
$\rho_{0}$ & -20.00 & 24.33 \\
$\rho_{1}$ & 0.58 & 0.23 \\
$\sigma_{\xi}$ & 135.00 & 28.46 \\
\hline
\end{tabular}

the first-stage estimating equations might lead to inconsistent estimates given the presence of lagged and current lift-height in those equations. Lagged values of virtual income, the number of service connections in each municipality, and artificial recharge were used along with twice-lagged rainfall observations as instruments. These instruments satisfy a $\chi^{2}$-test of the over-identifying restrictions with a $p$-value of 0.042. Demand equation estimates arising from these first-stage estimates imply a price-elasticity of -0.66 , evaluated at the sample-mean price for cities that do not charge zero marginal prices. This is in the feasible range suggested by micro-level studies of water demand.

The parameter estimates from the second (dynamic) stage of the process are presented in Table V. The global properties of the likelihood function were explored to insure that a local maximum was not being mistakenly reached by the nonlinear optimization routine, and standard errors for these second-stage parameter estimates were derived from the gradient of the likelihood function after taking a single step in the full space of sixty-eight parameters. Initial conditions for each city's net unobserved marginal revenue (i.e., $\xi_{i, 0}, i=1,2, \ldots, 13$ ) were in no case significantly different from zero. The inability of the estimation procedure to precisely estimate these initial conditions is not surprising and will not adversely affect the following counterfactual simulations and conclusions for welfare. These parameters do serve an important role, however, in that they allow the remaining structural parameters to be estimated in a model consistent with autocorrelated unobservables. Estimating the model under such a structure (i.e., as opposed to an i.i.d. unobservable structure) results in changes in those remaining parameters that are both statistically and economically significant.

The second-stage estimate of the convex-combination weighting parameter $v$ allows the null hypothesis of net surplus maximization (i.e., $H_{0}: v=1 / 2$ ) to be rejected easily. Moreover, simulations suggest that, at the margin, $\partial C S / \partial \pi=$ -0.453 , implying that municipal managers sacrifice the last dollar in benefits to taxpayers in exchange for only a $45 \notin$ gain to water consumers. Allocational efficiency would dictate that this trade-off be one-to-one. Making use of the continuous approximation to the conditional value function arising from this estimation procedure, the shadow value of groundwater in situ can also be derived from these structural parameters. Conditioning on a realization of $X_{i, t}$, the derivative of the conditional value function with respect to lift-height can be found at every point in $(h, \xi)$ space. Multiplication by the rate at which the removal of an 
acre-foot of water raises the lift-height yields the marginal value of an additional acre-foot of groundwater in the aquifer stock, given that managers continue to price in the future according to the same set of conditional policy functions:

$$
\left(\frac{\partial V\left(h_{i, t}, \xi_{i, t} \mid X_{i, t} ; \hat{\theta}_{1}\right)}{\partial h_{i, t}}\right) \cdot\left(\frac{\partial h_{i, t}}{\partial D_{i, t}}\right) .
$$

This expression was evaluated at each point in $\left(h_{i, t}, \xi_{i, t}\right)$ space and averaged over all $X_{i, t}$ in the data panel. Average shadow values range from approximately seventeen to thirty constant 1995 dollars per acre-foot.

\section{COUNTERFACTUAL SIMULATIONS OF EFFICIENT PRICING}

The preceding parameter estimates describe the pricing behavior of municipal managers observed within sample. By employing counterfactual parameter values, the welfare costs of inefficient pricing can be measured. In particular, simulations are used to quantify the increase in net aggregate surplus from pricing water to reflect its dynamic marginal production cost. These simulations reveal that such pricing yields significant gains relative to both continued current pricing behavior and (contrary to prior studies) pricing to reflect static marginal costs. The same simulation mechanism can also be used to study the effectiveness of (politically popular) nonprice conservation policies (e.g., rationing and mandatory low-flow appliance installations) under a regime of nonoptimally pricing municipal regulators (see Timmins (1999b)).

In conducting a simulation of efficient pricing, $X_{i, t}$ is forecast fifty years into the future via time series extrapolation. Given the structural parameter estimates found above, an assumed value for $\beta(0.95)$, and a set of initial conditions determined by observations in the closing year of the panel, ${ }^{12}$ the pricing decisions of a representative city and its subsequent lift-height realizations are simulated over the fifty-year horizon. Recognizing that $X_{i, t}$ and all stochastic processes enter the time-paths of price and lift-height nonlinearly, this process is repeated for one-hundred-eighty sets of independent random draws. The resulting sets of simulated paths are averaged to produce the mean predicted "current-behavior" price and lift-height series for that representative city.

The set of structural parameters that imply dynamic net surplus maximization are the same as those found by the estimation algorithm, with the exception of the common behavioral parameter $v$, which equals $1 / 2$. The simulation procedure is repeated under this counterfactual assumption, making use of the same expectational assumptions and random draws. This produces a set of predicted average "dynamic marginal cost pricing" paths for price and lift-height. Finally, the simulation procedure is repeated again under net surplus maximizing behavior and the same expectational assumptions and random draws, but attributing

\footnotetext{
${ }^{12}$ Note the following exceptions: (i) $\xi$ is arbitrarily set to 0.0 in the initial simulation year, and (ii) a large initial lift-height (i.e., 275 feet) is used to avoid random draws that become constrained by $h \geq 0$.
} 


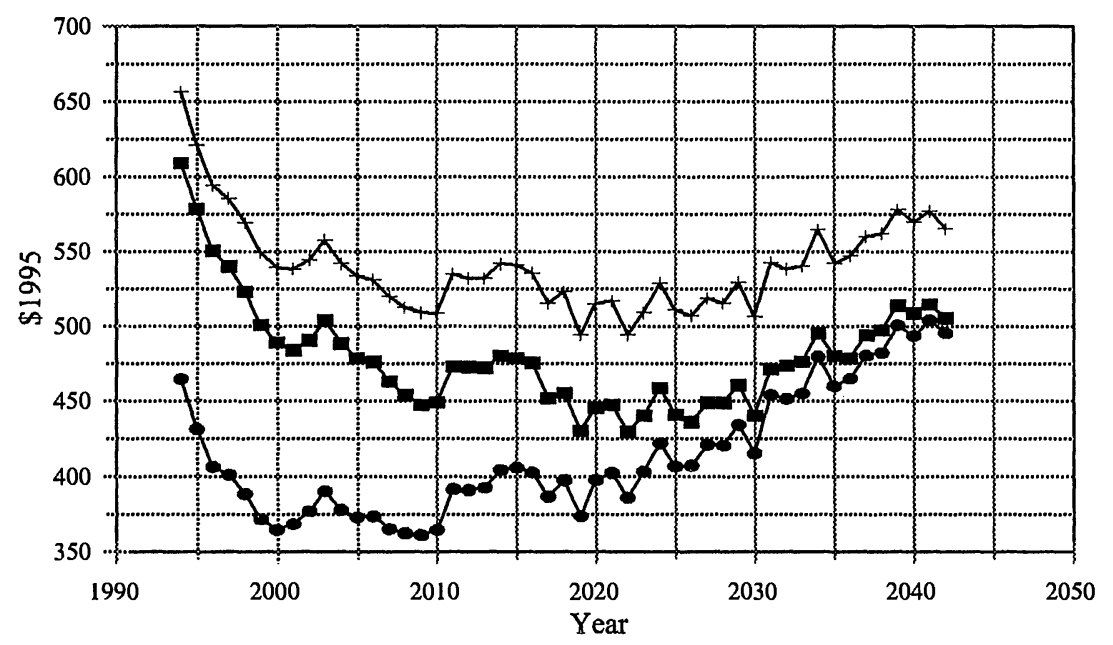

- Continued Current Behavior

$\rightarrow$ - Static Net Sumplus Maximization $\quad \longrightarrow$ Dynamic Net Surplus Maximization

FIGURE 3.-Predicted price paths.

to the municipality a myopic decision-making horizon $(\beta=0)$. This procedure yields a set of predicted average "static marginal cost pricing" paths for price and lift-height. Figures 3 and 4 portray the mean predicted "continued current behavior," "dynamic marginal cost pricing," and "static marginal cost pricing" paths for price and lift-height. ${ }^{13}$

Consider first the initial jump in price from that simulated under continued current behavior required to achieve dynamic marginal cost pricing; i.e., $\$ 464.96$ to $\$ 656.72$ per acre foot. This $41.2 \%$ increase yields a marginal price that falls well inside historical bounds established for water prices in other water-scarce cities in the West (California DWR (1994b, p.35)). Moreover, the accumulation of the resulting cutbacks in household use leads to a reduction in lift-height after fifty years of $26.1 \%$, measured relative to the simulated lift-height under continued current pricing. This could prove particularly valuable given the costs of aquifer depletion described in the introduction.

\footnotetext{
$1390 \%$ confidence bounds were also calculated for each of these paths. While the bounds on the estimated time paths of price (and, to a lesser extent, extraction and lift-height) were large, and while the point estimates were often insignificantly different from zero at traditional levels, the results were encouraging. In particular, they provide some information about the quality of the model's conclusions, and that quality will only increase with the sample size. In stark contrast, no meaningful bounds can be calculated for similar time-paths derived from calibration techniques, which use a single data point in model parameterization. In fact, confidence bounds derived from such procedures are infinite. Calibration techniques subject to this criticism have dominated previous studies of aquifer management (see, for example, Burt (1964a, 1964b, and 1967), Brown and Deacon (1972), Gisser and Sanchez (1980), Allen and Gisser (1984), Brill and Burness (1994), Knapp and Olsen (1995)).
} 


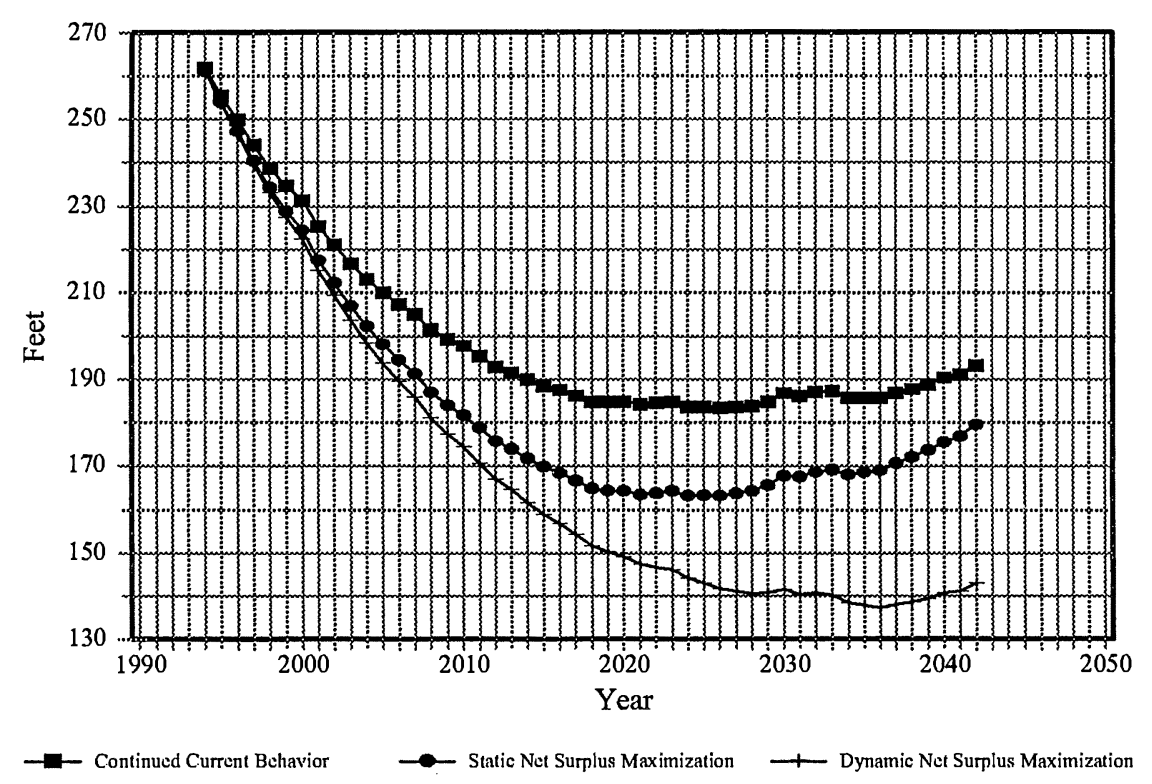

FIGURE 4.--Predicted lift-heights.

Recalling the graphical analysis in the introduction, the difference in the first simulated year between the dynamic and static efficient price per acre-foot (i.e., $\$ 656.72$ versus $\$ 609.24$ ) measures the expected present discounted value of the increase in future extraction costs resulting from that year's extraction activities (i.e., $M C_{1994}^{\prime}-M C_{1994}$ ). This difference of $\$ 47.48$ is not inconsequential; over the full simulation period, $54.2 \%$ of the difference between the dynamic efficient price and the price under continued current behavior is attributable solely to the recognition of these dynamic components of costs.

The importance of dynamic cost components in an efficient pricing policy can be seen clearly by examining the gain in net surplus achieved under a dynamic marginal cost pricing policy relative to that achieved under a static policy (i.e., by comparing $A^{\prime}$ to $A$, as defined in Figure 1). Given the parameter estimates in Table IV, static marginal cost $(M C)$ is a convex and increasing function of extraction. An analytical representation of the dynamic marginal cost curve, $M C^{\prime}$, is not available, but by assuming that dynamic marginal costs are a vertical translation of static marginal costs, an approximation of $A^{\prime}$ can be found. Under these assumptions, $A^{\prime}$ is, on average, 2.55 times bigger than $A$, making clear the importance of dynamic cost components. This result differs from prior work on the merits of dynamic versus static efficient control of groundwater stocks. For example, Gisser and Sanchez (1980) find that the difference between static 
and optimal dynamic management of a common pool "is so small that it can be ignored for practical purposes." 14

The distributional implications of these simulations indicate that dynamic marginal cost pricing imposes costs on municipal residents in their role as water consumers, but that they can be more than compensated in their role as taxpayers. Average per-household per-year magnitudes (i.e., found by taking an undiscounted average across all households in the fifty-year simulation horizon) demonstrate this fact: moving from the current pricing regime to one of dynamic marginal cost pricing implies a fall in average consumer surplus each year of $\$ 40.64$ per household, which is offset by an increase in average annual municipal profits of $\$ 151.32$ per household. Individuals are penalized in their role as water consumers, but gain enough as taxpayers and consumers of other municipal services to come out ahead by $\$ 110.68$ per household per year, which represents $52 \%$ of the average annual variable water revenues per household under current pricing behavior. ${ }^{15,16}$

\section{CONCLUSIONS}

This paper has quantified the net costs borne by the citizens of a groundwaterdependent municipality when its municipal managers, in satisfying some unspecified political objectives, fail to set water prices efficiently. These deadweight losses average $\$ 110.68$ per household per year in constant 1995 dollars. The marginal dollar of taxpayer benefits was shown to be sacrificed in exchange

${ }^{14}$ Gisser and Sanchez (1980), who derive their results from a calibrated model of the Pecos Basin in New Mexico that relies upon linear pumping-cost and agricultural water demand functions to obtain analytical descriptions of behavior, consider the difference between optimal control and competition among many agents drawing on a common pool. While I consider only single users of an aquifer, the implication of their results (i.e., that the dynamic cost consequences of stock-externality-driven over-extraction are negligible) are comparable to my results.

${ }^{15}$ Concern has been expressed with regards to these results and the large elasticity of demand (i.e., $\partial \operatorname{In} D / \partial \operatorname{In} P=-\delta_{1} \cdot P=-4.92$ ) exhibited when price equals dynamic marginal cost in the first simulation year (i.e., \$656.72). In order to test the robustness of these conclusions to the idiosyncrasies of the semilog demand specification, which was used to facilitate the presence of zero marginal prices in the data, but which induces this large price elasticity for high simulated prices, the same counterfactual simulations were performed with a semilog price elasticity of -1.64 at a price of $\$ 656.72$. These results imply a $361 \%$ initial jump in price from current behavior to reach a dynamically optimal price, and an average $96.9 \%$ markup over time. These price increases indicate an average reduction in consumer surplus per household of $\$ 97.50$, which is offset by an increase in average annual water utility profits per household of $\$ 731.18$, for a net surplus gain per household of $\$ 633.68$ each year.

${ }^{16}$ Note that this analysis has simplified away a number of factors that could prevent the described Pareto surplus improvements from being realized. Consider, for example, the possibility that bureaucratic waste dissipates any increased operating profits that result from efficient pricing. Moreover, the possibility exists that, without an appropriate redistribution of income, social welfare could actually fall despite the Pareto improvements in net surplus implied by efficient pricing. Future work on the formulation and implementation of efficient water pricing policies should address each of these issues. 
for only $45 \phi$ in gains to water consumers. These welfare calculations, moreover, ignore potential external benefits from reduced groundwater consumption, including increased groundwater quality, reduction in damage from subsidence and desertification, and improved supply stability. Contrary to the results of previous (calibrated simulation) studies of the merits of optimal control versus competitive management of aquifer stocks, the results of this paper also suggest that the component of net surplus gains explicitly attributable to recognizing the dynamic components of the costs of current extraction are significant, averaging more than $2 \frac{1}{2}$ times the size of the component of net surplus gains achieved from static efficient acquifer management. This paper provides a method for recovering estimates of these dynamic costs that makes efficient use of data on constrained pricing decisions. While simulations suggest that the standard errors on these estimated welfare effects are quite large, they are significantly smaller than those derived from a calibrated simulation model, and will only get smaller with additional data.

Department of Economics, Yale University, P. O. Box 208264, New Haven, CT 06520-8264,U.S.A.; christopher.timmins@yale.edu.

Manuscript received October, 1997; final revision received December, 2000.

\section{REFERENCES}

Agthe, Donald E., And Bruce R. Billings (1980): "Dynamic Models of Residential Water Demand," Water Resources Research, 16, 476-480.

Allen, Richard C., AND Micha Gisser (1984): "Competition Versus Optimal Control in Groundwater Pumping When Demand Is Nonlinear," Water Resources Research, 20, 752-756.

BARON, DAVID P. (1989): "Design of Regulatory Mechanisms and Institutions," in Handbook of Industrial Organization, Volume II, ed. by R. Schmalensee and R. D. Willig. New York: Elsevier Science Publishers, B.V.

BAron, David P., AND Roger B. Myerson (1982): "Regulating a Monopolist With Unknown Costs," Econometrica, 50, 911-930.

Billings, R. BRuCE (1982): "Specification of Block Rate Price Variables in Demand Models [Price Elasticities for Water: A Case of Increasing Block Rates]," Land Economics, 58, 386-394.

Brill, Thomas C., AND Stuart H. Burness (1994): "Planning Versus Competitive Rates of Groundwater Pumping," Water Resources Research, 30, 1873-1880.

Brown, GARDNER, JR., AND Robert DEACON (1972): "Economic Optimization of a Single-Cell Aquifer," Water Resources Research, 8, 557-564.

BURT, OsCAR (1964a): "The Economics of Conjunctive Use of Ground and Surface Water," Hilgardia, 36, 31-111.

(1964b): "Optimal Resource Use Over Time With an Application to Ground Water," Management Science, 11, 80-93.

(1967): "Temporal Allocation of Groundwater," Water Resources Research, 3, 45-56.

California Department of Finance (1970-1993): "Population Estimates of California Cities and Counties," Reports (70 E-1)-(93 E-1). Sacramento, CA: Department of Finance, Population Research Unit.

California Department of Water Resources (1994a): California Water Plan Update, Bulletin 160-93. Sacramento, CA: State of California DWR. DWR.

(1994b): Urban Water Use In California, Bulletin 166-4. Sacramento, CA: State of California 
California Department of Water Resources, San JoAquin District Office (1992): "Historical Unconfined Ground Water Trends in the San Joaquin Valley." Sacramento, CA: State of California DWR.

Carver, Philip H., AND John J. Boland (1980): "Short- and Long-Run Effects of Price on Municipal Water Use," Water Resources Research, 16, 609-616.

Cochran, Richard, AND ARThur W. CotTon (1985): "Municipal Water Demand Study, Oklahoma City and Tulsa, Oklahoma," Water Resources Research, 21, 941-943.

Diringer, Elliot (1991): "Deeper Wells and Saltier Water," San Francisco Chronicle, 4/17/91, p. A7.

Feigenbaum, Susan, And Ronald Teeples (1983): "Public Versus Private Water Delivery: A Hedonic Cost Approach," The Review of Economics and Statistics, 65, 672-678.

Feldman, Stephen L., John Breese, And Robert Obeiter (1981): "The Search for Equity and Efficiency in the Pricing of a Public Service: Urban Water," Economic Geography, 57, 78-93.

$\rightarrow$ Gisser, Micha, AND DAVID A. SANCHEZ (1980): "Competition Versus Optimal Control in Groundwater Pumping," Water Resources Research, 16, 638-642.

Howe, Charles W. (1982): "The Impact of Price on Residential Water Demand: Some New Insights," Water Resources Research, 18, 713-716.

Judd, KenNeTH L. (1998): Numerical Methods in Economics. Cambridge, MA: The MIT Press.

KNAPP, KeITH C., AND LARS J. Olson (1995): "The Economics of Conjunctive Groundwater Management with Stochastic Surface Supplies," Journal of Environmental Economics and Management, 28, 340-356.

MANn, PATRICK C., AND John L. Mikesell (1976): "Pricing by Rural Electric Cooperatives," Land Economics, 52, 96-102.

Martin, RANDOlPh C., ANd Ronald P. Wilder (1992): "Residential Demand for Water and the Pricing of Municipal Water Services," Public Finance Quarterly, 20, 93-102.

National Climatic Data Center: On-Line Data Access. Online, Internet, Available at http:// www.ncdc.noaa.gov/pub/data/coop-precip/california.txt.

PAKes, ArIEl (1994): "Dynamic Structural Models, Problems and Prospects: Mixed Continuous Discrete Controls and Market Interactions," in Advances in Econometrics, Sixth World Congress, Vol. II, ed. by Christopher Sims. Cambridge: Cambridge University Press.

$\rightarrow$ Peltzman, SAm (1971): "Pricing in Public and Private Enterprises: Electric Utilities in the United States," The Journal of Law and Economics, 14, 109-147.

RenZetti, Steven (1992): "Evaluating the Welfare Effects of Reforming Municipal Water Prices," Journal of Environmental Economics and Management, 22, 147-163.

Rust, JoHn (1994): "Estimation of Dynamic Structural Models, Problems and Prospects: Discrete Decision Processes," in Advances in Econometrics, Sixth World Congress, Vol. II, ed. by Christopher Sims. Cambridge: Cambridge University Press.

Stokey, NANCy L., AND Robert E. LuCAS, JR. (1989): Recursive Methods in Economic Dynamics. Cambridge, MA: Harvard University Press.

Swallow, Stephen K., AND CARlos M. MARIn (1988): "Long Run Price Inflexibility and Efficiency Loss for Municipal Water Supply," Journal of Environmental Economics and Management, 15, 233-247.

Teeples, Ronald, And David Glyer (1987): "Cost of Water Delivery Systems: Specification and Ownership Effects," The Review of Economics and Statistics, 69, 399-408.

Timmins, Christopher (1999a): "The Redistributive Fiscal Role of Residential Water Bills," Mimeo, Yale University Department of Economics.

(1999b): "Demand-Side Technology Standards Under Inefficient Pricing Regimes: Are They Effective Water Conservation Tools in the Long-Run?" forthcoming in Journal of Environmental and Resource Economics. 